\title{
LOS CAMINOS NO CONFORMES DE LA RAZÓN. ACERCAMIENTO TEÓRICO A LA CIENCIA FICCIÓN Y LA LITERATURA FANTÁSTICA A PARTIR DE DOS TEXTOS DE ADOLFO BIOY CASARES Y ALGUNOS CONCEPTOS MATEMÁTICOS
}

\author{
POR \\ ANOUCK LinCK \\ MCF Université de Caen Basse Normandie
}

Diferenciar la literatura de ciencia ficción de literatura fantástica no cuesta mucho; en cambio resulta mucho menos obvio comparar ambos géneros, o sea lograr mirarlos desde una perspectiva que, preservando especificidades, evidencie relaciones de semejanza y cierta complementariedad. Solemos colocarles la etiqueta de "géneros especulativos" por tratarse de relatos en los cuales la imaginación es fuertemente regulada por la lógica y el razonamiento. Empezaré, entonces, analizando el modo inusual en que se relacionan razón e imaginación en esos relatos. Eso me llevará a focalizar en el código hermenéutico definido por Barthes (1915-1980) y a establecer una curiosa correspondencia entre la terminología movilizada por el teórico francés y la terminología movilizada por los matemáticos cuando demuestran un teorema. Pondré a prueba los resultados obtenidos con dos textos de Adolfo Bioy Casares que pertenecen, respectivamente, a la ciencia ficción y a la literatura fantástica: su novela más famosa, La invención de Morel (1940), y un relato poco conocido titulado "Los afanes" (Historias fantásticas, 1972). Ambos tratan de un procedimiento técnico inventado para captar las almas, capaz de brindarle al hombre la oportunidad de sobrevivir, en ciertas condiciones, a su propia muerte. La finalidad de esta investigación no es trazar una línea divisoria entre ciencia ficción y literatura fantástica, sino adquirir herramientas metodológicas aptas para renovar nuestro acercamiento teórico a ambos géneros.

\section{UNA IMAGEN POSITIVA PERO IMPURA DE LA RAZÓN}

El relato de ciencia ficción se construye sobre un sustrato científico; el relato fantástico, en cambio, se afana por derrotar lo racional al introducir un acontecimiento o un hecho sobrenatural. Uno parece ser el aliado de la razón; el otro su antagonista. Pero esta visión sumaria merece ser matizada. La literatura fantástica y la de ciencia ficción 
exaltan ambas aspectos de la razón en los cuales no solemos hacer hincapié, porque enturbian su imagen oficial, la de una razón "pura" y "dura" que avanza en línea recta, segura de sí e inflexible, por un camino no improvisado hacia el conocimiento. Dicho de otro modo, esas dos formas narrativas vinculan, cada una a su manera, una imagen positiva pero impura de la razón.

\subsection{El caso de la ciencia ficción}

¿De dónde sacan sus ideas los autores de ciencia ficción? Sin duda, de la ciencia de su tiempo. Son, afirma Roland Lehoucq (1965), astrofísico francés apasionado de ciencia ficción, "ideas realistas o en curso de elaboración", pero al ser "estiradas, deformadas" por los escritores se transforman en algo mejor: una ficción. "Los autores son quienes fijan los límites de la ciencia en sus relatos; su imaginario no es, como el de los científicos, fundamentalmente restringido por la realidad". Poco importa, insiste Lehoucq, que el resultado sea científicamente plausible o no, "de hecho en la mayoría de los casos no lo es" (Lehoucq). Esa deformación, ese estiramiento de los que habla Lehoucq son analizados por Maurice Renard (1875-1939), escritor y teórico de ciencia ficción, en términos de lo "maravilloso-científico":

¿En qué difieren nuestras soluciones imaginarias de las verdaderas soluciones de la ciencia? Dicho de otro modo, (...) ¿cuál es la particularidad del razonamiento maravilloso-científico? Es la introducción voluntaria, en la cadena de proposiciones, de uno o varios elementos viciosos, cuya naturaleza determina, más adelante, la aparición del ser, o el objeto, o el hecho maravilloso. (Renard 1208) ${ }^{1}$

Jean Fabre (1927), especialista en literatura fantástica, comenta por su parte que en los relatos de ciencia ficción "[...] el estatuto de la técnica y del saber científico es comparable al de la magia" (Fabre 176):

Mientras que la ciencia, al evolucionar, va dejando huecos epistemológicos cada vez más vertiginosos, esa seudociencia verticalisante, al contrario, se asemeja a la causalidad mágica al pretender explicar fenómenos inexplicables, de una manera, por cierto, inadmisible (Fabre 68). ${ }^{2}$

1 "En quoi nos solutions imaginaires diffèrent-elles des véritables solutions de la science? En d'autres termes, [...] qu'est-ce qui distingue le raisonnement merveilleux-scientifique? C'est l'introduction volontaire, dans la chaîne des propositions, d'un ou de plusieurs éléments vicieux, de nature à déterminer, par la suite, l'apparition de l'être, ou de l'objet, ou du fait merveilleux".

2 "Alors que la Science, en évoluant, fait apparaître des vides épistémologiques de plus en plus vertigineux, cette pseudo-science verticalisante, au contraire, rejoint la causalité magique pour expliquer les phénomènes inexplicables, mais à sa manière, bien sûr irrecevable". 
La racionalidad es convocada en los relatos de ciencia ficción, de eso no cabe duda, pero es una racionalidad "adaptada" a la ficción. Basta pensar en la invisibilidad del profesor Griffin en la famosa novela de H.G. Wells, o en la capacidad de los précogs en utilizar su mente para visualizar el futuro en los cuentos de Philip K. Dick, o en la sensibilidad de los Jedis a la Fuerza en La guerra de las galaxias, para quedar convencidos. El razonamiento -puesto que sí lo hay- que pretende explicar esos fenómenos es "vicioso" e "inadmisible". Resulta que la imagen de la razón vinculada por los relatos de ciencia ficción es la de una tramposa, que pacta con ella misma sin poner las cartas sobre la mesa.

Lehoucq comenta además que la ciencia que inspira a los autores dista mucho de ser pura, clara, y de estar bien definida:

Los autores de ciencia ficción no se nutren de cosas que funcionan bien; sino de las que no son claras, ahí donde hay ebullición, espacios fronterizos, que provocan cuestionamientos (clonaje humano, dimensiones paralelas, etc.); zonas en que la ciencia está en proceso de elaboración. Y ellos parten del exterior y dejan que su imaginario construya lejos de lo asentado (Lehoucq). ${ }^{3}$

La razón es una tramposa, pero su causa es noble. Lo que importa es "mirar qué pasa" (Lehoucq), qué historia se puede construir a partir de esos visos de cientificidad. Jean Textier alias Jean Cabanel (1888-1957) comenta que el juego favorito de Maurice Renard "[...] es desmontar la maquinaria humana para cambiar de sitio los engranajes y mirar como funciona el instrumento armado así" (Cabanel). Los "arreglos" iniciales con la racionalidad permiten, de hecho, desarrollos inéditos y espectaculares.

En definitiva, ¿qué imagen de la razón vinculan los relatos de ciencia ficción? Sin duda sigue siendo una imagen positiva. Los universos originales, extraños pero "posibles" que se despliegan ante la mirada ávida y fascinada del lector son auténticas exploraciones racionales. Pero si tenemos en mente aquellos "arreglos" previos con las ideas científicas - que condicionan la emergencia de dichos universos, al empalmar la ciencia restringida por la realidad con la imaginación fantasiosa de los escritores- es también, innegablemente, una imagen impura.

"Les auteurs de science-fiction ne se nourrissent pas de choses qui fonctionnent bien; ils prennent les machins pas clairs, là où ça grouille, les trucs frontières, là où on se pose des questions (clonage humain, dimensions parallèles, etc.); les endroits où la science est en train de se construire. Et eux ils partent de l'ex-térieur et ils laissent leur imaginaire construire loin des assises scientifiques établies". 


\subsection{El caso del discurso fantástico}

Ahora bien, ¿cuál es la imagen de la razón que ofrecen los relatos fantásticos? El propósito de los siguientes párrafos es mostrar que ellos también sugieren una imagen positiva pero impura. Lo primero puede parecer irrealista. ¿A quién se le ocurriría pensar, cuando tiene entre las manos un cuento fantástico, que de él se desprende una imagen positiva de la razón? Poco importa que el evento sobrenatural sea cierto o no, su probabilidad se impone y que exista esa probabilidad basta para desacreditar a la razón. De hecho, parece como si el relato fantástico se las ingeniara para exhibir las carencias, las limitaciones del razonamiento, frente a la inasequible complejidad de lo real.

Uno puede perfectamente atenerse a esa imagen negativa de la razón. Pero no basta. Fabre describe el efecto fantástico como un "vértigo de la razón" (85): si se produce un vértigo, es porque la razón tiene un papel predominante. El discurso fantástico es un discurso "fundamentalmente heurístico" (Fabre, 96) cuya originalidad consiste en demostrar los límites del razonamiento. Dicho de otro modo: al exhibir los límites del razonamiento, exhibe posibilidades ocultas del mismo.

Hay por lo tanto dos maneras no excluyentes de considerar el papel de la razón en un relato fantástico. La primera, más bien negativa; y la segunda, más bien positiva. Es de notar que en este último caso la razón es pervertida, adulterada; se desvía del buen camino. El discurso fantástico la utiliza de un modo poco ortodoxo, que enturbia su imagen. El "buen" uso de la razón debería supuestamente desembocar en un conocimiento seguro. Pero el discurso fantástico no hace "buen" uso de la razón; hace "mal" uso de ella ya que el razonamiento subyacente a la lectura incita al lector a formular lógicamente una proposición contraria al sentido común y a la razón. Tal es la diabólica eficiencia del razonamiento a que se ve abocado el lector en los relatos fantásticos.

Una resonancia magnífica con el pensamiento científico ilustra ese poder a la vez pérfido e irrecusable del razonamiento. Tiene que ver con el célebre teorema de incompletitud de Kurt Gödel (1906-1978). Recordemos que Gödel, cuando enunció su teorema en 1931, aniquiló las recientes esperanzas de Cantor, Frege y Russell -por no citar a otros- que se habían esmerado, tras penosos trabajos, en asentar la totalidad de las matemáticas sobre fundamentos puramente lógicos. Gödel digitalizó el lenguaje y construyó la fórmula enigmática y no paradójica que dice acerca de sí misma: "soy indemostrable", probando así que existen, en el campo de las matemáticas, proposiciones cuya validez no puede ser probada desde el interior del sistema. ¡El método axiomático socavándose a símismo! Vaya manera retorcida de echar mano al razonamiento. Semejante proceder hace pensar en las estrategias igualmente retorcidas - e igualmente creativasdel discurso fantástico. Hasta el punto de atreverse uno a preguntarse si acaso los textos fantásticos del siglo XIX no constituyen una formidable anticipación, en el plano de la literatura, del teorema de Gödel: parece que se empeñaran en demostrar, antes de 
tiempo, los límites intrínsecos al método deductivo. La fórmula comúnmente asociada al acontecimiento fantástico - "imposible pero cierto"- presenta similitudes asombrosas con el teorema de Gödel, si sustituimos el adjetivo "imposible" por "indemostrable".

Llegamos, con esto, a la conclusión de que la literatura fantástica no vincula únicamente una imagen negativa de la razón, señalando sus carencias y limitaciones. Usa-y abusa-de la razón con provecho, revelando posibilidades ocultas, insospechadas y algo perversas del pensamiento. Como la ciencia ficción, pero a su manera, vincula una imagen positiva pero impura de la razón.

\section{Código Hermenéutico y teoría Deductiva}

El razonamiento parece imponerse como marca distintiva de la ciencia ficción y la literatura fantástica, no tanto por tratarse de géneros especulativos, sino sobre todo por su carácter no ortodoxo. Merece que ahondemos en él, en vistas a profundizar la comparación entre los dos géneros literarios que aquí nos interesan.

El razonamiento tiene una función precisa en el campo de las matemáticas. Una manera de aprovecharla y conectarla, sin desvirtuarla, con nuestra reflexión teórica, podría ser ayudándonos del código hermenéutico como de una pasarela. El código hermenéutico es, entre los cinco códigos textuales identificados por Barthes en $S / Z$, el que pone el lector en situación de "desciframiento activo" (Barthes 23). A medida que va leyendo, el lector especula, anticipa acontecimientos, imagina desenlaces: en otras palabras, se entrega a un acto (inconsciente) de demostración. En su búsqueda de "la verdad", se parece un poco al matemático que va, deducción tras deducción, explicitando las informaciones ocultas en las premisas.

Barthes decide llamar código hermenéutico "[...] al conjunto de unidades que tienen la función de articular, de diversas maneras, una pregunta, su respuesta y los variados accidentes que pueden preparar la pregunta o retrasar la respuesta, o también formular un enigma y llevar a su desciframiento" (12). ${ }^{4}$ El modo como se articulan los diferentes términos de un enigma recuerda la manera como se articulan los diferentes términos de una demostración matemática, aunque (claro) las exigencias formales no son comparables. El código hermenéutico culmina en una "proposición de verdad" -en el sentido que tiene en la lógica-:

La proposición de verdad es una frase "bien hecha"; comporta un sujeto (el tema del enigma), el enunciado de la pregunta (la formulación del enigma), el enunciado de la pregunta (la formulación del enigma), su marca interrogativa (el planteamiento del

\footnotetext{
4 "L'ensemble des unités qui ont pour fonction d'articuler, de di-verses manières, une question, sa réponse, et les accidents variés qui peuvent ou préparer la question ou retarder la réponse; ou encore: de formuler une énigme et d'amener son déchiffrement".
} 
enigma) y las diferentes subordinadas, incisas y catálisis (las dilaciones de la respuesta) que preceden al predicado final (la revelación). (Barthes 70$)^{5}$

Una teoría deductiva, en cuanto a ella, es una serie de deducciones, derivada de un sistema de axiomas, que culmina en un teorema final. La verdad de cualquier proposición se establece mediante una operación deductiva, o sea relacionándola lógicamente con otras proposiciones verdaderas o consideradas como tales. Propongo el siguiente desafío: mirar si las analogías entre código hermenéutico y teoría deductiva son sostenibles o resultan descabelladas.

Empecemos por la cuestión de la verdad. Para los matemáticos, la lógica es la verdad en acción. Para Barthes, el código hermenéutico es "la voz de la verdad". La verdad a la que se refiere es análoga a la de los matemáticos en el sentido en que no es general ni abstracta; es al contrario un resultado concreto, que se puede formular y descomponer en une serie de hipótesis relacionadas unas con otras y condicionadas por un conjunto de premisas.

Sigamos con las deducciones. Corresponderían, en la terminología de Barthes, a "las diferentes subordinadas, incisas y catálisis que preceden el predicado final (las dilaciones de la respuesta)". ¿Es sostenible la comparación? Las fórmulas bien formadas son el cuerpo de la teoría deductiva. Procedamos a enumerar y definir algunas. Un "teorema" es una aserción verdadera y demostrable de importante valor conceptual. Un "lema" es un teorema intermediario. Una "proposición" es una aserción o teorema menos significativo. Un "corolario" es el resultado directo de una aserción ya comprobada. Un "hecho" es una aserción sencilla o dada como evidente al estar referenciada en la bibliografía en la cual se asienta la demostración. Una “conjetura" es una propuesta cuya verdad o falsedad no ha sido demostrada, pero que se considera como verdadera y que, una vez demostrada, se vuelve teorema. La terminología es clara y precisa a la vez. Las correspondencias entre ambas terminologías saltan a la vista. Basta, para convencerse, pensar en algunos ejemplos concretos de "dilaciones" que Barthes enumera: falsa respuesta, respuesta eludida (o suspendida), respuesta parcial, respuesta bloqueada, engaño, equívoco.

Sigamos ahora con los axiomas. En matemáticas, son el conjunto de principios fundamentales e indemostrables de los cuales es derivable cada uno de los enunciados teoremáticos de la demostración. En literatura solemos hablar de "convenciones de lectura": naturalmente, ellas cumplirían el papel de axiomas en nuestro juego de correspondencias. Queda aún sin resolver la cuestión de las reglas de deducción.

\footnotetext{
5 On aboutit in fine à une "proposition de vérité"-proposition au sens où on l'entend en logique; la proposition de vérité est une phrase bien faite, elle comporte un sujet (le thème de l'énigme), l'énoncé de la question (sa formulation), sa marque interrogative (la position), les différentes subordonnées, incises et catalyses (délais de la réponse) qui précèdent le prédicat final (dévoilement).
} 
Contentémonos (por ahora) con decir que razonamos, en la inmensa mayoría de los casos, tanto en matemáticas como en literatura, siguiendo una lógica "clásica"; o sea una lógica entre cuyos principios fundamentales destaca el principio aristotélico de "no contradicción" (una proposición no puede ser falsa y verdadera al mismo tiempo).

Hacer "el inventario" del código hermenéutico consiste para Barthes: “[...] en distinguir los diferentes términos (formales), a merced de los cuales se centra, se plantea, se formula, luego se retrasa y finalmente se descifra un enigma (a veces esos términos faltarán, a menudo se repetirán; no aparecerán en un orden constante)" (14). ${ }^{6}$

Bien podríamos decir, habiendo llegado a este punto, que otra manera de hacer el inventario del código hermenéutico consiste, para el lector, en poner en claro la teoría deductiva que estuvo elaborando mientras estaba en situación de desciframiento.

Ahora bien, ¿cuál es el interés de semejante paralelo? Pues que nos obliga a focalizar en aspectos a los cuales por lo general no se les presta especialmente atención. Aspectos que el mismo Barthes consideraba superfluos: los principios fundamentales (axiomas) y las reglas de deducción (lógica movilizada). Ambos condicionan la red de deducciones formuladas por el lector. Y justamente por eso ambos tienen, en el caso de la ciencia ficción y la literatura fantástica, especial importancia. A ellos se debe en efecto el hecho de que el lector razone -contrariamente a lo que ocurre en la inmensa mayoría de sus otras lecturas- de una manera "no conforme".

\section{Dos relatos de Bioy Casares}

Llegó el momento de contrastar la teoría con los textos. Pondremos a prueba la utilidad y pertinencia de los resultados obtenidos mediante el análisis de los dos relatos de Bioy Casares mencionados en la introducción de este trabajo: La invención de Morel y "Los afanes" (Historias fantásticas).

\subsection{La invención de Morel}

En el caso de un relato de ciencia ficción, las premisas o axiomas sobre los cuales se fundamenta el razonamiento del lector son, naturalmente, los "arreglos" con la racionalidad antes mencionados; arreglos que consisten, como hemos visto, en estirar y deformar ideas científicas válidas o controvertidas para posibilitar desarrollos insospechados. Es de notar que algunas de las proposiciones formuladas por el lector en el curso de su razonamiento distan mucho de ser proposiciones teoremáticas básicas y

6 L'inventaire du code herméneutique consistera à distinguer les différents termes (formels), au gré desquels une énigme se centre, se pose, se formule puis se retarde et enfin se dévoile (ces termes parfois manqueront, souvent se répéteront; ils n'apparaîtront pas dans un ordre constant). 
descarnadas; al contrario, tienen implicaciones filosóficas y repercusiones emocionales; tanto más cuanto que entran en resonancia con invenciones recientes y teorías científicas relativamente populares.

La invención de Morel es una novela que data de 1940, pero no por ello es anticuada, pues abre-como veremos a continuación-cuestionamientos vigentes hoy en día. Morel presenta su invención a sus compañeros de la siguiente manera:

Mi abuso consiste en haberlos fotografiado sin autorización. Es claro que no es una fotografía como todas; es mi último invento. Nosotros viviremos en esa fotografía, siempre. Imagínense un escenario en que se representa completamente nuestra vida en esos siete días. Nosotros representamos. Todos nuestros actos han quedado grabados. (Bioy Casares, La invención 152)

Cuatro páginas de notas en papeles amarillos, reproducidas por el narrador en su diario, aportan las explicaciones necesarias. Morel justifica en una prosa "rica en palabras técnicas" pero sin embargo "clara" (154) su sistema "mecánico y artificial" (157) de reproducción de la vida. Relata cómo tuvo que "perfeccionar" tecnologías existentes (radiotelefonía, televisión, teléfono, cinematógrafo, fotografía, fonógrafo)-el lector toma nota de que Morel ha superado la ciencia "limitad[a]" (155) de su época. Los acontecimientos misteriosos; las extrañezas de la historia; todo encuentra, a la luz de las explicaciones de Morel, su justificación. Dichas explicaciones constituyen un buen ejemplo razonamiento maravilloso-científico; pero lo que está en juego, lo que se está pactando, es que el lector se plantee la existencia de la máquina de Morel como un hecho. Si el lector conviene de ello, encuentra (por fin) en la máquina de Morel el modo de fundamentar una teoría deductiva coherente y se impone entonces la dimensión ciencia ficcional del relato.

La máquina inventada por Morel importa menos, por más fascinante que sea, que las alteraciones que autoriza dentro del orden habitual de las cosas y sus subsecuentes cuestionamientos éticos y filosóficos. Morel "[...] estaba seguro de que [sus] simulacros de personas carecerían de consciencia de sí (como los personajes de una película cinematográfica)" (156-157) pero pronto cambia de opinión: “[...] congregados los sentidos, surge el alma. Había que esperarla. Madeleine estaba para la vista, Madeleine estaba para el oído, Madeleine estaba para el sabor, Madeleine estaba para el olfato: Ya estaba Madeleine" (157). ¿Son conscientes las imágenes que reproduce la máquina? ¿Hasta qué punto son humanas? Si los logros tecnológicos volvieran factible la inmortalidad, ¿sería por ello deseable? Son "las viejas preguntas" (157) de siempre -atañen al sentido de la vida, la definición de la consciencia, las fronteras de lo vivo, etc.- pero planteadas desde una perspectiva capaz de reactualizarlas y aportar respuestas nuevas. Esa capacidad a descentrar nuestra mirada es, a mi parecer, una de las ventajas mayores de la ciencia ficción. 
Uno asiste frecuentemente, en los relatos de ciencia ficción, a la fabricación de robots humanoides u otras criaturas artificiales complejas. Lo usual es partir de la materia inerte para crear algo vivo; Bioy Casares invierte el procedimiento habitual. En este sentido, toma un camino abierto por avances recientes en el campo de las biotecnologías y las nanotecnologías. Salvo que en el relato, la hibridación del hombre y de la máquina no da lugar a una expansión del ser sino a un cercenamiento: los "sosias inverosímiles" (156) fabricados a partir de "emisores vivos" (157) son un trozo de éstos últimos. Ni siquiera es seguro que su supervivencia bajo la forma de imágenes incluya una porción de alma: eso es una simple "hipótesis" que "[...] parece confirmada por los efectos de [la] máquina" (158). Es más, suponiendo -lo que nunca se podrá comprobar-que las copias conservan los pensamientos y las sensaciones que experimentaron los sujetos originales, no por ello dejarían de ser lo que son: unos autómatas. Jean-Claude Heudin (1957), científico francés especializado en inteligencia artificial, define a los autómatas de la manera siguiente:

Los autómatas son mecanismos que son programados de cierta manera [...] pero lo importante, es que esas secuencias programadas son fijas, y que pase lo que pase en el entorno del autómata, éste repetirá invariablemente la misma secuencia; no hay interacción entre los observadores o el entorno y este autómata. (Heudin) ${ }^{7}$

Semejante descripción resalta lo "atroz" de la "eternidad rotativa" (169) a la cual Morel y sus compañeros están condenados. Las imágenes actúan, obedecen, se comportan como sofisticados autómatas; como autómatas, es menester activarlas. Lo son, periódicamente, por las máquinas, que funcionan gracias a la potencia de las mareas. Simultáneamente, los hombres pueden, en cualquier momento, recluirlas "[...] en la posibilidad inútil de sus máquinas desconectadas" (167).

El hombre siempre ha soñado con ser inmortal. Ese deseo de inmortalidad ha estimulado desde tiempos remotos la investigación científica. La eternidad "inestable" (111) imaginada por Bioy Casares es una ficción, pero entra en resonancia con invenciones recientes y teorías científicas actuales que, al integrarse a la red de proposiciones elaboradas por el lector, ensanchan las potencialidades del texto. Daré dos ejemplos.

Morel compara la tercera parte de su máquina (la que materializa las imágenes) con "un proyector cinematográfico" (156). Pero el avance tecnológico autoriza hoy nuevas comparaciones. El carácter tridimensional de las imágenes y su capacidad para engañar los sentidos -"ningún testigo admitirá que son imágenes" (156)- hace pensar

7 Les automates sont des mécanismes qui sont programmés d'une certaine manière $[\ldots]$ mais le point important c'est que ces séquences programmées, elles sont fixes, et quoi qui se passe dans l'environnement de l'automate, il répétera indéfiniment la même séquence, il n'y a pas d'interaction entre les observateurs ni l'environnement et cet automate. 
en las bioimpresoras 3D. Una impresora 3D es una máquina relativamente difundida hoy en día. No necesita, como tampoco la máquina de Morel, "[...] pantallas ni papeles; sus proyecciones son bien acogidas por todo el espacio y no importa que sea día o noche" (156). Para mayor información veamos a Joël de Rosnay (1937), biólogo francés especialista en prospectiva. El explica primero cómo funcionan esas máquinas; y después evoca las más fascinantes, las bioimpresoras 3D:

Actualmente la gran fase del internet por la que estamos pasando es una digitalización. [...] Transformamos átomos, moléculas, en bits electrónicos que circulan en los computadores, en las redes, en internet; esos bits sirven para los mails, para imprimir documentos, etc. [...] Pero la digitalización del internet del futuro, es el paso de los bits a los átomos y a las moléculas: con bits digitalizados, que están dentro del computador previamente conectado a una impresora 3D, que vemos dar vueltas en la pantalla, con solo marcar print podemos fabricar objetos en tres dimensiones. [...] La etapa mientras se va materializando el objeto sólido es muy impresionante. ${ }^{8}$ (De Rosnay)

"Y ahora" agrega De Rosnay en un impulso oratorio que recuerda a Morel presentando su máquina, “iempieza a haber bioimpresoras 3D! Que no utilizan plástico, sino células vivas". Imprimir un órgano, fabricar un órgano directamente imprimiéndolo, no será posible de una día para el otro, pero la ciencia está trabajando en ello, y De Rosnay cita nombres, da ejemplos concretos de avances, hace notar cómo ese sector apasiona a los industriales de la farmacéutica y la cosmética. De hecho, parece que la ciencia sí logrará un día fabricar órganos artificiales con células vivas, y esa perspectiva tiene incidencias en nuestra visión del hombre del futuro. Nuestros órganos vitales serán tal vez, mañana, reproductibles como piezas de lego. ¿Un hombre armable y desarmable como si fuera de piezas montables sigue siendo humano? De Rosnay plantea la pregunta, pero también se la plantea el lector, cuando imagina a Madeleine convertida en una serie de "ondas y vibraciones" (155) sincronizadas.

El segundo ejemplo de resonancia con la ciencia actual tiene que ver con el transhumanismo. Morel se aseguró una "eternidad agradable" (153) inventando una máquina capaz de congregarlo y "recomponer[lo]" (163) al ser activada. Investigadores como el norteamericano Ray Kurzweil (1938) y el inglés Aubrey de Grey (1963) son, como Morel, unos “inmortalistas”. Kurzweil está convencido de que en años venideros se

Actuellement la grande phase internet dans laquelle nous sommes est une numérisation. [...] On transforme des atomes, des molécules, en bits électroniques qui circulent dans les ordinateurs, dans les réseaux, sur internet; ces bits servent pour les emails, à imprimer des documents, etc. [...] Mais la numérisation internet de demain, c'est le passage des bits aux atomes et aux molécules: en utilisant des bits numériques qui sont sur des ordinateurs connectés à une imprimante $3 \mathrm{D}$, en les voyant tourner sur l'écran et en mettant print, on fabrique des objets en trois dimensions. [...] Le stade du passage à la pièce solide est très impressionnant. 
dará, en el desarrollo tecnológico, un aceleramiento repentino y ultra rápido en el campo de las nanotecnologías y la informática: él llama ese momento de inflexión tecnológica "el punto de singularidad". Kurzweil es un transhumanista, y piensa que cuando se dé ese momento, habrá llegado la hora para la humanidad de robotizarse (Kurzweil). Pronostica que el hombre y la máquina estarán en ese entonces inextricablemente mezclados, siendo los órganos o las partes dañadas reemplazados, conforme irán fallando, por órganos artificiales mejorados, de modo que la vida humana se perpetuará mucho más allá de los límites actuales. Hasta el día en que la inmortalidad "[pueda] germinar en todas las almas" (163): en otras palabras, hasta el día en que los logros tecnológicos permitan almacenar la conciencia en un disco duro bajo la forma de bits. El hombre vuelto cyber podrá entonces "vivir" eternamente; será, de alguna manera, inmortal (al menos mientras exista una copia de seguridad).

El protagonista de la novela de Bioy Casares está convencido, como hoy los transhumanistas, que "[...] la conservación indefinida de las almas en funcionamiento está asegurada" (164). Asegurada, ¿pero para quiénes? Esta pregunta se plantea tanto en la novela como en la realidad. Es una pregunta filosófica, ética; económica también, porque algunas personas dispondrán de los recursos económicos necesarios para aumentar considerablemente la duración de su vida y otras no. Ricos y pobres no son iguales ante la muerte -sería ingenuo pensarlo- pero esa desigualdad de por sí escandalosa podría en el futuro aumentar drásticamente. ¿Por qué puso Morel tanto cuidado en mantener secreta su invención y preservar su isla de eventuales intrusos, a no ser para salvaguardar la conservación de su "paraíso privado"? (162). La inmortalidad, tanto en la novela como en la realidad, es el privilegio de unos pocos. La voluntad de "perpetuación" (166) de los transhumanistas es, para De Rosnay, "extraordinariamente elitista, extraordinariamente egoísta" porque puede desembocar en la constitución de dos categorías de humanos: "[...] los aumentados y los no aumentados; los inmortalizados y los no inmortalizados. [...] Es una visión que no es ética, a lo mejor es apasionante en el plano científico, pero va un poco en contra de la naturaleza" (De Rosnay) en medida en que la muerte condiciona la vida y es su contraparte natural.

Esos dos ejemplos de resonancia entre ciencia ficción y ciencia actual ilustran la diversidad y la complejidad de las ramificaciones posibles del razonamiento. Ahora bien, las bioimpresoras 3D y el transhumanismo son "hechos", al igual que la máquina de Morel; salvo que son tomados "afuera" del relato e insertados en la red de inferencias elaborada el lector. Los hechos, en una teoría deductiva, encuentran su justificación en la "bibliografía". La terminología de Barthes relativa al código hermenéutico no permite encontrar correspondencias con el campo de la teoría literaria. Pero otros teóricos, tales como Wolfgang Iser (1926-2007) y más recientemente Milagros Ezquerro (1943), pueden ayudar. La noción de "repertorio" propuesta por Iser en el marco de su teoría 
de la recepción o la noción de "idiotopo $\Omega$ " propuesta por Ezquerro en el marco de su reflexión sobre el texto son, en este sentido, funcionales. Las potencialidades del árbol del razonamiento son inmensas y complejas, pues queda claro que sus raíces se expanden mucho más allá de las que exhibe el texto.

Es curioso como aquel relato tan breve, escrito hace más de medio siglo, sigue estimulando la capacidad reflexiva del lector. Al sumergirse en la historia, el lector entra en resonancia con problemas éticos, filosóficos y políticos (en el sentido noble de la palabra) relacionados con avances recientes de la ciencia de los cuales Bioy Casares no tenía la más remota idea. Semejantes resonancias son uno de los logros más estimulantes de la ciencia ficción. Y se dan por caminos no conformes del razonamiento - esto lo tenemos ya claro-porque la historia imaginada por el autor tiene como punto de partida el estiramiento y la amplificación de ideas científicas válidas o controvertidas que abren cuestionamientos interesantes.

\section{2. "Los afanes" (Historias fantásticas)}

Preguntémonos ahora cuál es el origen de la no conformidad del razonamiento en el caso de los relatos fantásticos. Quedó establecido más arriba que la originalidad de dicho género es llevar el lector a formular, en el marco de su teoría deductiva, una proposición indemostrable; dicho de otro modo, lo lleva a formular una proposición cuya verdad no es derivable de los axiomas. Esos axiomas, ¿cuáles son? Se reducen a lo que Fabre llama el "postulado de horizontalidad", o sea esa convención inicial que manda ver las cosas desde una perspectiva racional, usando el sentido común.

Es obvio que semejante postulado descarta lo sobrenatural. No obstante lo sobrenatural-o la eventualidad de lo sobrenatural-se impone. Todo gira, en el fondo, en torno a la paradoja lógica que consiste en autorizar la presencia de una contradicción-o la eventualidad de una contradicción- en el cuerpo de la teoría. Tal es la particularidad del discurso fantástico: implica al lector en la elaboración de una teoría no consistente pero coherente, dentro de la cual no vale el principio aristotélico de no contradicción (recordemos que una teoría sometida a ese principio se "trivializa" apenas aparece una contradicción o la sombra de una contradicción).

El fantasma de la contradicción no impide que el lector elabore una teoría coherente, por lo tanto existe una lógica que se adapta a su razonamiento. ¿Dónde buscarla? Algunos lógicos, como el ruso Nicolai A. Vasiliev (1880-1940), el norteamericano de origen polaco Emil Post (1897-1954), Jan Lukasiewicz (1878-1956) y Stanislaw Jaskowski

9 El idiotopo $\Omega$ del observador "es un sistema complejo, abierto, en constante comunicación con sus contextos; por eso es evolutivo y móvil, aunque tiene características y estructura propias. Está constituido de los elementos psico-biográficos de la persona del observador, y de todos los componentes contextuales que han podido influirlo" (39). 
(1906-1965), ambos polacos, se atrevieron a poner en tela de juicio, al principio del siglo $\mathrm{XX}$, el absolutismo del principio de no contradicción, negando los efectos explosivos de una contradicción (ex contradictione sequitur quodlibet). Que haya una contradicción en el cuerpo de una teoría es una cosa, pero que se puedan derivar de esa contradicción todos los enunciados posibles es otra. Ellos fueron los primeros en abrir un tercer camino, admitiendo que una teoría puede comportar una contradicción y al mismo tiempo resistir a las implicaciones nefastas que supone el principio de no contradicción. Hoy en día, Jaskowski y los demás son considerados como los precursores más importantes de la lógica paraconsistente, una lógica enteramente formalizada dentro de la cual el principio de contradicción no es válido (o está restringido a ciertas fórmulas).

Para Louis Vax (1924), "lo fantástico se nutre de un escándalo de la razón” (29). Desde cierto punto de vista, el de la lógica más usual, tiene razón: es chocante que una teoría que contenga una contradicción sea coherente. Pero si uno se pone bajo la égida de una lógica más flexible, menos restrictiva, como por ejemplo la lógica paraconsistente, la paradoja desaparece. La no conformidad del razonamiento elaborado por el lector no se origina, esta vez, en los axiomas, sino en la lógica movilizada: una lógica paraconsistente, que autoriza la presencia de una contradicción y sus consecuentes ramificaciones. ¡Vaya duplicidad del género fantástico! Se supone (postulado de horizontalidad) que para razonar hay que atenerse al sentido común, pero de hecho, una lógica superior, más englobante, garantiza la coherencia de la demostración.

Tzvetan Todorov (1939) considera que "[...] sólo lo atribuido al autor escapa a la prueba de la verdad" (87-88). En la inmensa mayoría de los relatos fantásticos, el autor adopta una focalización interna. Que el relato esté o no escrito a la primera persona, los acontecimientos son presentados desde el punto de vista, necesariamente incompleto y subjetivo, de un personaje: "su" verdad no es nunca, pues, absolutamente cierta. Uno "supone" que es cierta, porque por la manera en que se expresa, en que percibe la realidad, parece ser una persona sensata y normal, pero hay que admitir que el punto de vista adoptado, incompleto y restrictivo, no basta para dar cuenta enteramente de la realidad. Así es como se impone, en la inmensa mayoría de los relatos fantásticos, el postulado de horizontalidad: dejando un espacio abierto por donde puede colarse la contradicción.

Bioy Casares, en su cuento titulado "Los afanes" (1972), no contraviene a la regla. El protagonista narrador está obsesionado desde la infancia por su amigo Eladio Heller, rico y muy superior en inteligencia; sus inventos lo cautivan y repelen a la vez. Transcurren los años, Eladio sale con Milena, la amiga del grupo, pero sigue acaparado por sus estudios. "Mientras uno duerme -protestaba Milena- él estudia. ¿Qué estudia? Las miserias que Dios puso en la oscuridad de los cuerpos, para que nadie las vea" (217). El narrador, absorto en compromisos familiares y preocupaciones personales, pierde de vista a su amigo, hasta el día en que le avisan que "[...] el pobre Heller entró 
en una etapa de franco disloque. Dicen que anoche fue a una reunión de espiritistas" (219). "Quedé medio enfermo" (220) confiesa el narrador tras haber verificado la información, porque asistió años atrás a una de esas reuniones y conserva un recuerdo traumático. Intenta enseguida hablar con Eladio, pero es Milena -quien ahora es su mujer- la que lo recibe. Heller es un monstruo, le anuncia, furiosa, y para convencerlo, lo lleva al garaje y lo pone delante de un bastidor que desprende un fuerte olor a perro. El narrador identifica inmediatamente el olor: es el de Marconi, el perro de Eladio, su viejo compañero; un sin fin de recuerdos relacionados con el animal lo inunda de repente. "Para que en el bastidor uno sienta un perro, Eladio estudió durante años, descuidó a hijos y mujer, sacrificó al amigo [...]" (223) resume Milena con tono de sarcasmo, y abriendo la puertita del bastidor, le muestra, colgado de un gancho, el cuero del pobre perro. ¿Heller es un monstruo? ¿Habrá que poner fin a sus actividades? El narrador se la pasa debatiendo el caso con sus amigos, pero Heller muere a los pocos días, volviendo inútil la discusión. Lo raro, es que el muerto parece ejercer una influencia apaciguadora sobre los vivos: en la sala de la casa de Milena, los amigos, la familia, experimentan los unos hacia los otros sentimientos bondadosos, los malos pensamientos se apagan en el acto, los antiguos rencores se desvanecen. Diego, el hermano de Heller, le confía un día al narrador que Eladio le habla, lo llama, quiere explicarle algo importante. El narrador vacila: el joven tiene "[...] el inconfundible tono de la verdad" (228). Decide entonces sacar las cosas en claro, regresar a la sala de Milena, aprovechar "[...] la oportunidad de averiguar si [hay] otra vida" (229). Pero se retrasa la ejecución de su proyecto, porque está enamorado de Milena y ella monopoliza su pensamiento; también porque se comprometió en pasar las vacaciones con su familia. El día en que regresa a Buenos Aires, se encuentra de nuevo con Diego, que anda hecho un loco. Diego lo pone al tanto de los acontecimientos de los últimos días: Eladio siguió llamándolo, hasta que él por fin se resolvió a escucharlo. Eladio le contó que, tras una pelea con Milena que lo mortificó mucho, transcribió su alma a un bastidor (previamente disimulado dentro de un busto sobre la chimenea); y le pidió a él, Diego, que lo protegiera y salvaguardara su invención. Estaba a punto de explicarle, desde el bastidor, cómo transferir el alma de los hombres (la facultad de pensar) para ponerla a salvo de la destrucción y la muerte-es un procedimiento técnico, un alma se transmite a un bastidor como "[...] un sonido a una antena de radio o una imagen a una antena de televisión” (231). Pero Diego habló con Milena y ella, enfurecida, buscó el bastidor donde estaba guardada el alma de Eladio, lo encontró, lo aplastó a pisotones. La oportunidad de conocer la verdad se perdió para siempre. Al finalizar su relato, Diego se va, pero antes le entrega al narrador el otro bastidor, el que huele a perro, donde el alma del viejo Marconi está atrapada, sin duda, en una negra eternidad.

Los acontecimientos, en este relato, son presentados desde un punto de vista parcial e incompleto. Las circunvoluciones del narrador, su falta de diligencia para buscar 
respuestas, dejan al lector insatisfecho, sin nada a qué agarrarse para comprobar la hipótesis. El narrador se parece a los "famosos" de Julio Cortázar (1914-1984): para ellos como para él, las cuestiones fundamentales pasan al segundo plano; lo primero son las preocupaciones cotidianas y las manías personales. Se siente intranquilo, pero no lo suficiente como para determinarse a dar la espalda a sus obligaciones inmediatas. Su postura es comprensible, adaptada a la realidad de cada día. Abandonarla, para ponerse a investigar fenómenos inexplicables y algo espeluznantes, significa arriesgar su equilibrio mental. “¿Cómo puede uno tomar en serio los afanes, los compromisos cotidianos, la ambición, que mueve al hombre, si hay otra vida, si nos movemos entre espíritus?" (220). Decididamente, cuesta demasiado renunciar al postulado de horizontalidad. El lector, atrapado en el punto de vista del narrador, siente sin embargo la intranquilidad apoderarse de él también. Los hechos -la presencia difusa de Marconi, las sensaciones experimentadas en la sala de Milena, el testimonio de Diego, las explicaciones de Heller avaladas por su genio indiscutible, la conmoción experimentada años atrás durante la sesión de espiritismo- lo obligan a formular una conjetura absurda desde el punto de vista del sentido común: a saber, la supervivencia del pensamiento de Eladio en " [...] un aparatito con dos columnas de níquel, de unos veinte centímetros de altura" (230).

Por su propia voluntad, Eladio Heller se redujo a "una inmortalidad ridícula". Eso es "abominable", como opina Milena, pero es también, hay que reconocerlo, una cosa muy "rara" (234). El narrador regresa a su rutina: el bastidor que Milena no alcanzó a romper pasa a ser "una curiosa peculiaridad" (235) y nada más. Pero el lector se siente raro, se siente "paraconsistente", porque su razonamiento lo ha llevado a formular lógicamente una conjetura que choca contra la empecinada resistencia del sentido común. Se puede calificar esa conjetura de "fantástica".

El sentido común, es la encarnación de la razón en su aspecto más ponderado, más moderado, más conforme. Es adaptado para la vida cotidiana, pero obviamente no es el que impulsa el conocimiento. La que impulsa el conocimiento, es la razón creativa e imaginativa, la razón no conformista y audaz, que no se ciñe a los límites asignados. La conjetura fantástica hace pensar en las "locas" hipótesis que los inventores, en vísperas de una revolución científica, se atreven a formular. Cristaliza el momento en que se franquean viejas barreras, sin saber qué hay detrás; en que la razón salta, por decirlo así, en el vacío. Parece absurda, disparatada, contraria a la razón, pero de hecho ayuda, como dice Cortázar, a situarse mejor o más lúcidamente en el mundo:

Quiero decir que un claro sentimiento del absurdo nos sitúa mejor y más lúcidamente que la seguridad de raíz kantiana según la cual los fenómenos son mediatizaciones de una realidad inalcanzable pero que de todas maneras les sirve de garantía por un año contra toda rotura. (26) 
Considerar, como lo hemos venido haciendo, lo sobrenatural como un vector de racionalidad, escandalizaría sin lugar a dudas los autores del siglo XIX; a aquellos que, como Guy de Maupassant (1850-1893), buscaban ante todo sumergir las almas de sus lectores en la perplejidad y el espanto. Pero Kafka (1883-1924) emprendió, con La metamorfosis (1913), un giro histórico en la evolución del género, al integrar francamente la contradicción en el razonamiento. Antes la contradicción bloqueaba el pensamiento; su efecto era paralizante, como la Medusa; ahora que es asumida, le hace experimentar al lector "el sentimiento del absurdo" descrito más arriba por Cortázar. "[...] es un sentimiento al alcance de la mano, nacido de cosas tangibles o demostrables, casi consolador. Ya no hay que creer porque es absurdo, sino que es absurdo porque hay que creer" (26).

\section{CONCLUSIÓN}

Los relatos fantásticos y de ciencia ficción tienen una cosa en común: ambos extienden los límites tradicionalmente asignados a la razón, siguiendo caminos no conformes. La ciencia ficción, al estirar y transformar ideas científicas válidas o controvertidas, explora ramificaciones improbables del pensamiento. El discurso fantástico, al postular un racionalismo estrecho, pero emancipándose de él introduciendo una conjetura inderivable, inicia al lector en el manejo de una lógica no clásica.

Establecer correspondencias entre el código hermenéutico y una teoría deductiva permite focalizar en la "base" del razonamiento (axiomas y lógica movilizada) y así evidenciar criterios útiles para definir ambos géneros y asentar la especificidad de cada uno. Esos criterios también dejan constancia de la capacidad y disposición del hombre para inventar. "Para nacer, las ideas nuevas necesitan que les echen una manita para extirparse de la normalidad" (106), afirma el físico francés Etienne Klein (1958-...). En ese sentido, a la base del razonamiento que uno elabora cuando lee un relato fantástico o de ciencia ficción, hay siempre como un delirio de la imaginación del autor. Pero "[...] el delirio debe ser estrictamente controlado para tener la menor oportunidad de desembocar en algo que valga la pena. Aunque [...] sea grande, permanece a fin de cuentas organizado y parece ser el fruto de una reflexión general" (Luminet 172). ${ }^{10}$ El astrofísico francés Jean-Pierre Luminet (1951-...) llama esa aptitud "dominio del delirio" y la presenta como una prerrogativa de los grandes descubridores en el campo de la ciencia; Borges, en su famoso prefacio a La invención de Morel, la transfiere al campo de la literatura y la denomina "imaginación razonada".

${ }^{10}$ Le délire ne peut être que strictement contrôlé pour avoir la moindre chance d'aboutir à quelque chose de valable. Même si le délire est grand, il reste somme toute organisé et paraît le fruit d'une réflexion générale. 


\section{BiBLIOGRAFÍA}

Barthes, Roland. S/Z. Buenos Aires: Siglo XXI editores, 2004.

Bioy Casares, Adolfo. La invención de Morel. Madrid: Cátedra, 1999.

"Los afanes". Historias fantásticas. Madid: Alianza, 1996. 213-235.

Cabanel, Jean. "Maurice Renard, père du merveilleux-scientifique". Le tryptique 24 (París, 1930).

Cortázar, Julio. La vuelta al día en ochenta mundos. Madrid: Siglo XXI editores, 1970 .

De Rosnay, Joël. “Organes artificiels : 1'homme en pièces détachées”. Conferencia. Cité des Sciences et de l'Industrie, París. Martes 14 mayo 2013.<http://www.carrefourdu-futur.com/conférences/organes-artificiel-1-homme-en-pièces-détachées/ $>$.

Ezquerro, Milagros. Leerescribir. ADEHL. México/París: ADEHL, 2008.

Fabre, Jean. Le miroir de sorcière. Essai sur la littérature fantastique. París: J. Corti, 1992.

Heudin, Jean-Claude. "Où vont les robots? La science historique et culturelle". Conferencia. Cité des Sciences et de l'Industrie. 6 nov. 2010. <http://www. franceculture.fr/plateformes-des-robots-et-des-hommes-ou-vont-les-robots.html $>$.

Iser, Wolfgang. El acto de leer. Teoría del efecto estético. Madrid: Taurus, 1987.

Klein, Etienne. "Le voile et la dérive". Sciences et imaginaire. París: Bibliothèque Albin Michel, 1994. 104-117.

Kurzweil, Ray. "We Are Becoming Cyborgs". Kurzweil. Accelerating intelligence. 15 mayo 2002. <http://www.kurzweilai.net/we-are-becoming-cyborgs>.

Lehoucq, Roland. "Quelles sont les limites de la science dans la science-fiction?". Conferencia.Palais de la découverte(París). 16 dic. 2008. <http://www.pourlascience. fr/ewb_pages/a/article-les-limites-de-la-science-dans-la-science-fiction-19845. php>.

Luminet, Jean Pierre. "Clair obscur radiatif". Sciences et Imaginaire. Ilke Angela Maréchal, dir. Albin Michel. Paris, 1994.

Renard, Maurice. "Du roman merveilleux-scientifique et de son action sur l'intelligence du progres"[1909]. Romans et contes fantastiques. París: Laffont, 1990. 1205-1213.

Todorov, Tzvetan. Introduction à la littérature fantastique. París: Seuil, 1970.

Vax, Louis. L'art et la littérature fantastiques. París: PUF, 1960. 
